\title{
Glutamate Uptake into Synaptic Vesicles: Competitive Inhibition by Bromocriptine
}

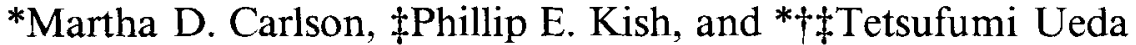 \\ The Departments of *Pharmacology and $\uparrow P$ sychiatry and the $\$$ Mental Health Research Institute, \\ The University of Michigan, Ann Arbor, Michigan, U.S.A.
}

\begin{abstract}
The ATP-dependent uptake of L-glutamate into synaptic vesicles has been well characterized, implicating a key role for synaptic vesicles in glutamatergic neurotransmission. In the present study, we provide evidence that vesicular glutamate uptake is selectively inhibited by the peptide-containing halogenated ergot bromocriptine. It is the most potent inhibitor of the agents tested; the $\mathrm{IC}_{50}$ was determined to be $22 \mu \mathrm{M}$. The uptake was also inhibited by other ergopeptines such as ergotamine and ergocristine, but with less potency. Ergots devoid of the peptide moiety, however, such as ergonovine, lergotrile, and methysergide, had little or no effect. Although bromocriptine is known to elicit dopaminergic and serotonergic effects, its inhibitory effect on
\end{abstract}

vesicular glutamate uptake was not mimicked by agents known to interact with dopamine and serotonin receptors. Kinetic data suggest that bromocriptine competes with glutamate for the glutamate binding site on the glutamate translocator. It is proposed that this inhibitor could be useful as a prototype probe in identifying and characterizing the vesicular glutamate translocator, as well as in developing a more specific inhibitor of the transport system. Key Words: Glutamate-Synaptic vesicle-ATP-dependent uptake-Ergots-Competitive inhibition-Glutamate translocator. Carlson M. D. et al. Glutamate uptake into synaptic vesicles: Competitive inhibition by bromocriptine. J. Neurochem. 53, 1889-1894 (1989).
It is now widely accepted that glutamate functions as a major excitatory neurotransmitter in the vertebrate CNS (for reviews see Watkins and Evans, 1981; Cotman et al., 1981; Fonnum, 1984; Ueda, 1986; Cotman et al., 1987; Nicholls, 1989) and at the neuromuscular junction of arthropods (Usherwood, 1981). The neurotransmitter glutamate is released from nerve terminals on their depolarization in a calcium-dependent manner (Bradford et al., 1973; Reubi and Cuénod, 1979; Cotman et al., 1981; Levi et al., 1982). Nicholls and Sihra (1986) have provided evidence that a noncytosolic pool of glutamate is rapidly released in a $\mathrm{Ca}^{2+}$ dependent manner, suggesting a role for synaptic vesicles in glutamate synaptic transmission. Glutamate has been shown to be specifically taken up into highly purified, isolated synaptic vesicles in an ATP-dependent manner (Naito and Ueda, 1983, 1985; Maycox et al., 1988), in accord with the immunocytochemical evidence that glutamate is concentrated in synaptic vesicles in certain nerve endings that are distinct from $\gamma$-aminobutyric acid (GABA)-rich nerve terminals
(Storm-Mathisen et al., 1983). The vesicular glutamate uptake is driven by an electrochemical proton gradient, which is generated by a proton pump Mg-ATPase, and stimulated by physiologically relevant concentrations of chloride (Naito and Ueda, 1985; Maycox et al., 1988; Shioi et al., 1989). The high degree of specificity and the unique properties of the vesicular glutamate uptake system have led to the proposal that whether or not glutamate is utilized as a neurotransmitter is determined by the presence or absence of the glutamatespecific vesicular translocator (Ueda, 1986). Recent studies by Fischer-Bovenkerk et al. (1988) suggest that the vesicular glutamate system is present in cerebellar granule cells, which are considered to be glutamatergic, but not in GABAergic Purkinje cells. Moreover, such a vesicular uptake system has been shown to develop in close parallel with the time course of synaptogenesis (Kish et al., 1989a). These lines of evidence all point to the importance of the vesicular glutamate uptake system in glutamate synaptic transmission. In this study, we have begun to investigate pharmacological
Received January 30, 1989; revised manuscript received May 16, 1989; accepted May 17, 1989.

Address correspondence and reprint requests to Dr. T. Ueda at Mental Health Research Institute, The University of Michigan, 205 Washtenaw Place, Ann Arbor, MI 48109, U.S.A.
Abbreviations used: GABA, $\gamma$-aminobutyric acid; RCSV, rat crude synaptic vesicles. 
means by which the vesicular glutamate transport system can be modulated. We provide evidence suggesting that the peptide-containing halogenated ergot bromocriptine may serve as a prototype agent for developing a more specific, potent regulator of the vesicular glutamate transport system.

\section{MATERIALS AND METHODS}

\section{Materials}

L-Glutamic acid (potassium salt), ATP, bromocriptine, $\alpha$ ergocriptine, ergonovine, and ergotamine tartrate were purchased from Sigma. Ergocristine methanesulfonate and dihydroergocriptine (Sandoz Pharmaceuticals) were generously provided by Dr. Edward Domino, Department of Pharmacology, the University of Michigan. Fluphenazine was a gift from E. R. Squibb and Sons, Princeton, NJ, U.S.A.; chlorpromazine was from $\mathrm{Smith}$, Kline, and French, Philadelphia, PA, U.S.A.; and lergotrile was from Eli Lilly, Indianapolis, IN, U.S.A. Methysergide, trifluoperazine, sulpiride, lysergic acid diethylamide, and bromolysergic acid diethylamide were provided by Dr. James Woods, Department of Pharmacology, the University of Michigan. L- $\left[2,3-{ }^{3} \mathrm{H}\right]$ Glutamic acid (36 Ci] mmol), 4-amino- $n-\left[2,3-{ }^{3} \mathrm{H}\right]$ butyric acid $(50 \mathrm{Ci} / \mathrm{mmol})$, and $\left[2-{ }^{3} \mathrm{H}\right]$ glycine $(19 \mathrm{Ci} / \mathrm{mmol})$ were obtained from Amersham.

\section{Preparation of synaptic vesicles}

Rat crude synaptic vesicles (RCSV) were prepared as described by Kish and Ueda (1989). In brief, rat cerebrum was homogenized in solution A $(0.32 M$ sucrose, $0.5 \mathrm{~m} M$ calcium acetate, $1 \mathrm{mM}$ magnesium acetate, and $1 \mathrm{mM} \mathrm{NaHCO}_{3}$ ) and centrifuged at $12,100 \mathrm{~g}_{\max }$ for $20 \mathrm{~min}(10,000 \mathrm{rpm}$. Sorvall SS-34 rotor). The pellet was lysed for $45 \mathrm{~min}$ in $6 \mathrm{~m} M$ Trismaleate $\left(\mathrm{pH} \mathrm{8.1)}\right.$ and centrifuged at $43,500 \mathrm{~g}_{\max }$ for $15 \mathrm{~min}$ (19,000 rpm, Sorvall SS-34 rotor). The supernatant was centrifuged at $200,000 g_{\max }$ for $50 \mathrm{~min}(47,000 \mathrm{rpm}$, Beckman TI 50 rotor) to pellet the synaptic vesicles. This crude vesicle preparation, which was resuspended in solution $\mathrm{B}(0.32 \mathrm{M}$ sucrose, $1 \mathrm{~m} M$ dithiothreitol, $1 \mathrm{~m} M \mathrm{NaHCO}_{3}$ ), was used in most of the experiments to be described here, except where otherwise indicated. Although there was some ATP-independent glutamate uptake activity in the RCSV preparation, it represented only about $10 \%$ of the ATP-dependent uptake activity.

\footnotetext{
Assay for vesicular glutamate uptake

Vesicular glutamate uptake was assayed essentially as described previously by Naito and Ueda (1983, 1985). The standard incubation mixture for the glutamate uptake contained, in a final volume of $100 \mu \mathrm{l}, 50 \mu \mathrm{g}$ of RCSV, $5 \mathrm{mM}$ Tris-maleate ( $\mathrm{pH} 7.4), 4 \mathrm{mM} \mathrm{MgSO}_{4}, 0.25 M$ sucrose, $2 \mathrm{mM}$ L-aspartate, 0 or $2 \mathrm{mM}$ ATP neutralized with Tris-base, 4 $\mathrm{mM} \mathrm{KCl}$, and $50 \mu M$ potassium $\mathrm{L}-\left[{ }^{3} \mathrm{H}\right]$ glutamate $(0.4 \mathrm{Ci} /$ $\mathrm{mmol}$ ). Aspartate was included to block any glutamate uptake into resealed plasma membrane vesicles, and to block any binding to glutamate receptors occurring from any plasma membrane contamination in the crude synaptic vesicle preparation used in these experiments. Synaptic vesicles $(10 \mu \mathrm{l}$ containing approximately $50 \mu \mathrm{g}$ of protein) and the Tris/ sucrose medium $(70 \mu \mathrm{l})$ were preincubated at $30^{\circ} \mathrm{C}$ for $5 \mathrm{~min}$ and then mixed with $20 \mu \mathrm{l}$ of a prewarmed glutamate/ATP mixture including the $\mathrm{KCl}$ and $\left[{ }^{3} \mathrm{H}\right]$ glutamate. The mixture was incubated for an additional $1.5 \mathrm{~min}$. The glutamate uptake was terminated by the addition of $2.0 \mathrm{ml}$ of ice-cold $0.15 \mathrm{M} \mathrm{KCl}$, followed by immediate filtration through Mil-
}

lipore HAWP filters ( $25 \mathrm{~mm}, 0.45 \mu \mathrm{m}$ ). The incubation tubes were washed with the $\mathrm{KCl}$ solution three times, and the filters were then washed four more times. Radioactivity retained on the filters (dpm) was determined in ACS (Amersham) by using a liquid scintillation spectrophotometer (Beckman LS 9000 ). The amounts of radioactive glutamate nonspecifically bound to the filters were determined as follows: the prewarmed $\left[{ }^{3} \mathrm{H}\right]$ glutamate/ATP mixture was mixed with $2.0 \mathrm{ml}$ of $\mathrm{KCl}$ solution and filtered; the filters were then washed with the $\mathrm{KCl}$ solution five more times. The radioactivity retained on the filters $(400-900 \mathrm{dpm})$ was subtracted from all of the values presented in the uptake experiments described here. The means \pm SEM of triplicate determinations were presented. All glutamate uptake values presented represent ATPdependent uptake activity, which was defined as the activity observed in the presence of ATP minus the activity observed in its absence, unless otherwise indicated. Synaptic vesicle protein was determined according to Lowry et al. (1951) with bovine serum albumin used as standard.

\section{RESULTS}

\section{Effects of ergots on vesicular glutamate uptake}

Figure $1 \mathrm{~A}$ and $\mathrm{B}$ shows the results of an experiment in which a number of derivatives of ergot alkaloids were tested for their effects on the ATP-dependent uptake of glutamate into RCSV. Bromocriptine, an ergot with dopamimetic properties (Fuxe et al., 1978; Kebabian and Calne, 1979), in micromolar concentrations, caused a marked inhibition of ATP-dependent glutamate uptake into RCSV. Bromocriptine was the most potent inhibitor of glutamate uptake of the various ergot derivatives tested, with an $\mathrm{IC}_{50}$ of $22 \pm 6$ $\mu M . \mathrm{IC}_{50}$ values (the concentration of inhibitor that inhibited $50 \%$ of the ATP-dependent glutamate uptake activity) were obtained by log-logit transformation of the data in Fig. 1A and B. In other experiments not shown here, however, the potent dopamine agonist apomorphine $(100 \mu M)$ did not inhibit glutamate uptake. Moreover, inhibition of glutamate uptake was not observed with any of the dopamine antagonists tested (at concentrations up to $500 \mu M$ ): trifluoperazine, fluphenazine, chlorpromazine, and sulpiride (data not shown). In addition, this inhibitory effect on glutamate uptake by bromocriptine was not mimicked by any of the serotonergic agonists or antagonists tested (at $500 \mu M$ ): lysergic acid diethylamide, bromolysergic acid diethylamide, and methysergide (not shown). These observations suggest that the inhibitory effect of bromocriptine is not mediated through dopamine or serotonin receptor mechanisms.

Bromocriptine is structurally classified as a peptide alkaloid or ergopeptine, containing a peptide moiety attached to the ergoline ring structure (Rall and Schleifer, 1980). To determine whether the inhibitory effect of bromocriptine is attributable to the ergoline ring structure, the peptide moiety, or to both, the various ergot compounds were tested for their ability to inhibit the ATP-dependent glutamate uptake. As shown in Fig. 1, those ergots that possess peptide moieties, e.g., ergotamine $\left(\mathrm{IC}_{50}=30 \pm 2 \mu M\right), \alpha$-ergocriptine $\left(\mathrm{IC}_{50}\right.$ 

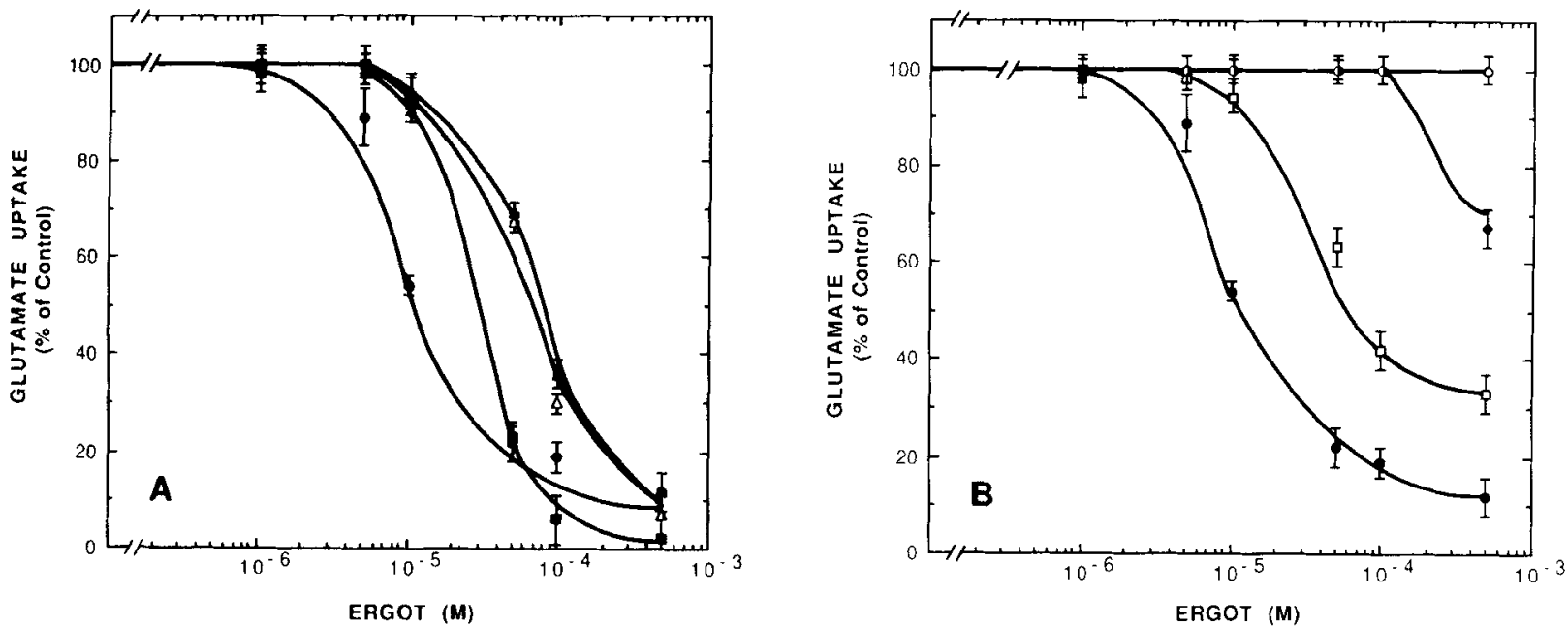

FIG. 1. Effects of various concentrations of ergots on ATP-dependent glutamate uptake into synaptic vesicles. A: Glutamate uptake was determined in the presence of various concentrations of bromocriptine $(\Theta)$, $\alpha$-ergocriptine $(\Delta)$, ergotamine $(\boldsymbol{D})$, and dihydroergocriptine $(\Delta)$. B: Glutamate uptake was determined in the presence of various concentrations of bromocriptine (๑), ergocristine ( $\square$ ), ergonovine (O), and lergotrile $(\bullet)$, as described in Materials and Methods. $\left[{ }^{3} \mathrm{H}\right]$ Glutamate uptake activity is expressed as percent of the activity in the absence of test agent (control). The giutamate uptake in the control was $11.5 \pm 0.24 \mathrm{pmol} / 1.5 \mathrm{~min}$. All of the ergots except ergonovine and lergotrile were dissolved in $50 \%$ or $75 \%$ (for $\alpha$-ergocriptine only) ethanol to make a stock solution of $10 \mathrm{~m} M$. Ethanol alone at a concentration of $0.5 \%$ (the concentration used for $10^{-4} \mathrm{M}$ ergot), or less, had no effect on glutamate uptake. Ethanol at $2.5 \%$, the concentration used for $500 \mu M$ ergot, lowered the glutamate uptake $42 \%$. This control value was used to determine the effect of this concentration of waterinsoluble ergot. The data on bromocriptine and the other ergots are representative of five and three individual experiments, respectively. The various ergots inhibited the ATP-independent uptake 5-10\% only at the two highest concentrations of ergot tested (100 and $500 \mu M$ ).

$=57 \pm 10 \mu M)$, dihydroergocriptine $\left(\mathrm{IC}_{50}=73 \pm 3\right.$ $\mu M)$, and ergocristine $\left(\mathrm{IC}_{50}=83 \pm 9 \mu M\right)$, were all effective but less potent than bromocriptine in inhibiting glutamate uptake. In contrast, those ergots that lack peptide moieties, such as lergotrile $\left(\mathrm{IC}_{50}>500\right.$ $\mu M)$ and ergonovine $\left(\mathrm{IC}_{50}>1 \mathrm{mM}\right)$, had little or no effect. The presence of the bromine moiety also appears to enhance the potency of the inhibitory effect on glutamate uptake, because $\alpha$-ergocriptine, which is identical to bromocriptine except that it lacks the bromine moiety, has a reduced potency. Therefore, it appears that both the peptide and bromine moieties attached to the ergoline ring structure are important in causing a potent and selective inhibition of ATP-dependent glutamate uptake.

\section{Nature of the bromocriptine inhibition}

Figure 2 shows a time course of glutamate uptake in the absence and presence of bromocriptine, following the standard 5-min preincubation time with the ergot. Bromocriptine showed its inhibitory effect throughout the incubation times tested; however, the effect decreased in magnitude with increasing incubation time. A preincubation time of $30 \mathrm{~s}$ is sufficient to achieve a maximal inhibitory effect by a given concentration of bromocriptine (data not shown), suggesting that full interaction between bromocriptine and a component of the glutamate uptake system occurs within $30 \mathrm{~s}$.

Figure 2 also shows that bromocriptine inhibited ATP-dependent glutamate uptake but had no significant effect on ATP-independent uptake. The values (approximately $2 \mathrm{pmol} / 50 \mu \mathrm{g}$ protein) obtained in the absence of ATP might represent glutamate binding to nonvesicular membrane proteins and/or to enzymes involved in the metabolism of glutamate. In an effort to determine whether bromocriptine interacts with the glutamate translocator component, kinetic experiments were carried out in the absence and presence of 10 and $20 \mu M$ bromocriptine. As shown in Fig. 3, the $V_{\max }$ of

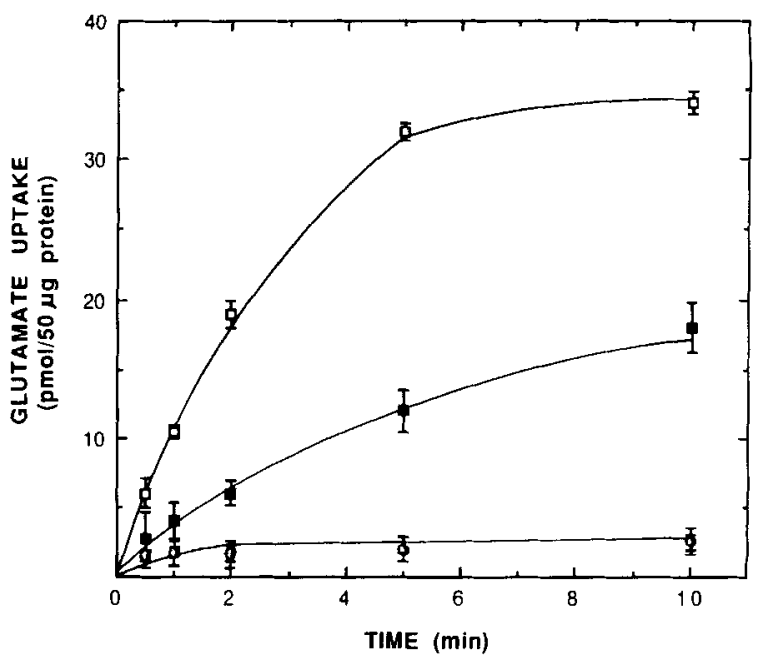

FIG. 2. Time course of vesicular glutamate uptake in the presence or absence of bromocriptine. Synaptic vesicles were preincubated at $30^{\circ} \mathrm{C}$ for $5 \mathrm{~min}$ in the absence $(\square, O)$ or presence $(\square, 0)$ of 100 $\mu M$ bromocriptine. A mixture of $\left[{ }^{3} \mathrm{H}\right]$ glutamate with ATP $(\square, \nabla)$ or without ATP $(O$, ) was then added, and glutamate uptake was allowed to occur for the various times indicated. The data are representative of two individual experiments. 
glutamate uptake was determined to be $0.26 \pm 0.02$ $\mathrm{nmol} / \mathrm{min}$ in both the absence and presence of 10 or $20 \mu M$ bromocriptine. Corresponding $K_{\mathrm{m}}$ values were $2.05 \pm 0.04,4.41 \pm 0.06$, and $6.10 \pm 0.09 \mathrm{mM}$, respectively. Thus, the inhibitory action of bromocriptine is reflected in a change (increase) in the $K_{\mathrm{m}}$ for glutamate, and not in changes in the $V_{\max }$ of the uptake system. These results suggest that the nature of the inhibitory effect on glutamate uptake by bromocriptine is competitive with respect to glutamate.

Other experiments not presented in this study failed to support the possibility that bromocriptine inhibits glutamate uptake by inhibiting the Mg-ATPase hydrolysis activity in the synaptic vesicle. Bromocriptine (1$100 \mu M$ ) exhibited no effect on the Mg-ATPase activity. Moreover, the degree of the bromocriptine inhibition was not affected by varying the concentration of ATP from 0.05 to $2 \mathrm{mM}$. These studies lend further support to the notion that the glutamate translocator is the site of action of bromocriptine.

\section{Effect of bromocriptine on ATP-dependent vesicular uptake of GABA and glycine}

The amino acids GABA and glycine are also taken up into synaptic vesicles in an ATP-dependent manner (Kish et al., 1987, 1988, 1989b; Fykse and Fonnum, 1988; Hell et al., 1988). These uptake systems are distinct from each other and from the glutamate uptake system (Kish et al., 1989b). In an effort to substantiate the selective action of bromocriptine on the glutamate translocator, we have examined the effect of the ergot on the ATP-dependent vesicular uptake of GABA and

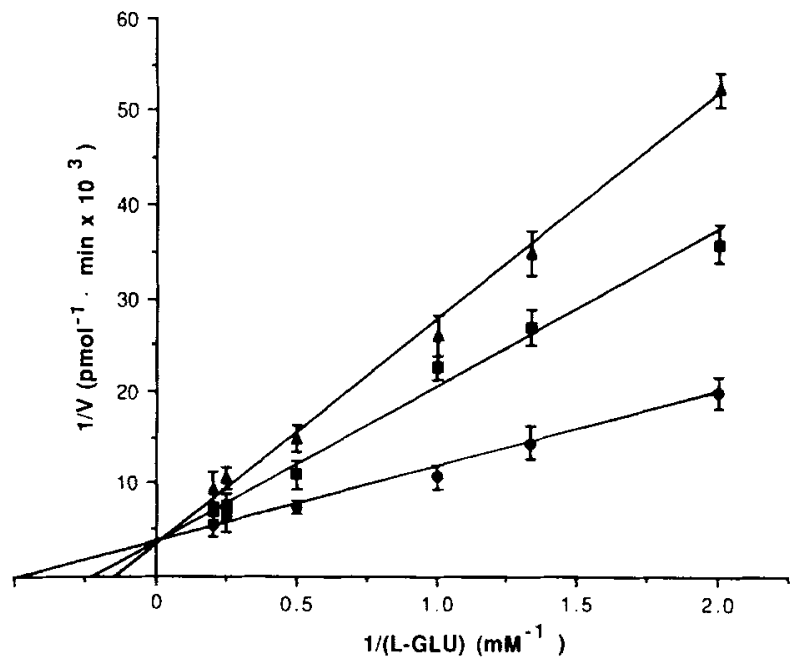

FIG. 3. Effect of bromocriptine on the kinetic parameters of the ATP-dependent vesicular uptake of glutamate. The vesicular glutamate uptake was determined at various concentrations of glutamate $(0.5-5 \mathrm{mM})$ in the absence (๑) or presence of $10 \mu \mathrm{M}$ bromocriptine ( $(\square)$ or $20 \mu M$ bromocriptine ( $\Delta$ ), as described in Materials and Methods. Specific activities of $\left[{ }^{3} \mathrm{H}\right]$ glutamate were $0.04 \mathrm{Ci} /$ $\mathrm{mmol}$ for $0.5 \mathrm{mM} ; 0.027 \mathrm{Ci} / \mathrm{mmol}$ for $0.75 \mathrm{mM}$; and $0.05,0.025$, 0.013 , and $0.01 \mathrm{Ci} / \mathrm{mmol}$ for $1,2,4$, and $5 \mathrm{mM}$ glutamate, respectively. The data are representative of three individual experiments. Intercepts were determined by linear regression analysis. glycine in comparison with the effect on vesicular glutamate uptake. As shown in Table 1, the inhibitory effect of bromocriptine is greater on the glutamate uptake system than on the GABA and glycine uptake systems. There was some inhibition by bromocriptine of the ATP-independent uptake activity; the inhibition of glutamate uptake in the cerebral synaptic vesicles and spinal cord vesicles was 2 and $8 \%$, respectively, and the inhibition for both GABA and glycine uptake was $8 \%$. These results suggest that the inhibitory action of bromocriptine is selective for the ATP-dependent glutamate uptake system.

\section{DISCUSSION}

In this study, we have demonstrated that bromocriptine selectively inhibits the ATP-dependent glutamate uptake into synaptic vesicles. The kinetic data shown in Fig. 3 indicate that the nature of bromocriptine's inhibitory action on uptake is competitive, with respect to glutamate, in that the $V_{\max }$ of glutamate uptake is unchanged, whereas the $K_{\mathrm{m}}$ for glutamate is increased. These results suggest that bromocriptine is acting at the glutamate translocator site of the synaptic vesicle, thereby preventing the uptake of glutamate into synaptic vesicles.

Bromocriptine's competitive interaction at the glutamate translocator site is substantiated further by studies that demonstrated that increasing the concentration of glutamate attenuated bromocriptine's ability to inhibit the vesicular glutamate uptake (data not presented). The competitive inhibition of glutamate uptake by bromocriptine also appears to be reversible, because removal of bromocriptine by centrifugation followed by incubation and subsequent centrifugation of the synaptic vesicles in the presence of high concentrations of glutamate (e.g., $50 \mathrm{mM}$ ) reversed the inhibitory effect of bromocriptine (not shown). This supports the view that the bromocriptine interaction with the glutamate translocator is via noncovalent bonding.

Other experiments not presented in this study suggested that bromocriptine does not inhibit the $\mathrm{Mg}$ ATPase hydrolysis activity in the synaptic vesicle. In addition, using the fluorescent probes Oxonol VI and Acridine Orange, which are indicators of membrane potential (Russell, 1984) and $\mathrm{pH}$ gradients (Xie et al., 1983), respectively, we observed that bromocriptine had no detectable effect on the membrane potential or $\mathrm{pH}$ gradient across the synaptic vesicle membrane (results not shown).

Although bromocriptine is known to mimic some of the dopaminergic and serotonergic effects, this study indicates that the inhibitory effect on vesicular glutamate uptake is not attributable to its dopaminergic and serotonergic properties. The data in Fig. 1 demonstrate that the tripeptide moiety of bromocriptine is crucial in achieving potent inhibition of glutamate uptake. Thus, ergonovine, which is devoid of the peptide moiety, exhibited no effect even at $1 \mathrm{~m} M$, the highest 
TABLE 1. Effect of bromocriptine on ATP-dependent amino acid neurotransmitter uptake into synaptic vesicles

\begin{tabular}{llccc}
\hline $\begin{array}{c}\text { Source of } \\
\text { synaptic vesicles }\end{array}$ & $\begin{array}{c}\text { Amino acid } \\
\text { neurotransmitters }\end{array}$ & - Bromocriptine & + Bromocriptine & $\begin{array}{c}\text { Inhibition } \\
(\%)\end{array}$ \\
\hline \multirow{2}{*}{ Cerebrum } & Glutamate & $82,825 \pm 1,542$ & $21,565 \pm 373$ & 74 \\
& GABA & $3,145 \pm 305$ & $2,284 \pm 307$ & 27 \\
Spinal cord & Glutamate & $79,216 \pm 1,294$ & $28,947 \pm 860$ & 63 \\
& Glycine & $13,032 \pm 932$ & $9,322 \pm 601$ & 28 \\
\hline
\end{tabular}

In the experiments in the upper half, crude synaptic vesicles were prepared from rat cerebrum as described by Kish and Ueda (1989) and purified further by discontinuous sucrose-density gradient $(0.4,0.6$, and $0.8 \mathrm{M}$ sucrose) centrifugation at $141,400 \mathrm{gmax}_{\max }$ for $120 \mathrm{~min}(28,000 \mathrm{rpm}$, SW 28 rotor), and $100 \mu \mathrm{g}$ of vesicle protein were used per assay. In those in the lower half, synaptic vesicles were purified from rat spinal cord by Percoll-density gradient centrifugation as described by Kish et al., (1989b), and $150 \mu \mathrm{g}$ of vesicle protein were used per assay. Vesicular amino acid uptake was assayed as described previously by Kish et al. (1989b), using $150 \mu \mathrm{ML}$ - $\left[{ }^{3} \mathrm{H}\right]$ glutamate, $\left[{ }^{3} \mathrm{H}\right] \mathrm{GABA}$, or $\left[{ }^{3} \mathrm{H}\right] \mathrm{glycine}$ (each $0.13 \mathrm{Ci} /$ $\mathrm{mmol}$ ), using $10 \mathrm{mM}$ ATP in the absence or presence of $100 \mu \mathrm{M}$ bromocriptine (in $0.5 \%$ ethanol) in the standard incubation medium described for glutamate uptake in Materials and Methods, except that $0.5 \%$ ethanol was included in the control and the assay volume was $200 \mu \mathrm{l}$. Uptake was allowed to occur for $5 \mathrm{~min}$ at $30^{\circ} \mathrm{C}$. The data are representative of two separate experiments; the variation in the percent inhibition from this experiment was $5-14 \%$.

concentration tested, whereas all the ergots containing the peptide moiety tested are capable of inhibiting the glutamate uptake at much lower concentrations. The bromine moiety appears to enhance the inhibitory potency.

Consistent with the notion that bromocriptine interacts with the vesicular glutamate translocator is evidence that the halogenated ergot selectively inhibited the glutamate uptake. Thus, GABA and glycine uptakes were less affected (Table 1). In addition to its interaction with the vesicular glutamate uptake system, bromocriptine has been reported to inhibit the high-affinity glutamate reuptake system in striatal membranes (Nieoullon et al., 1982). However, in contrast to its effect on the vesicular uptake system, the inhibition appeared to be achieved through activation of $\mathrm{D}_{2}$-like dopamine receptors located on the presynaptic corticostriatal glutamatergic nerve endings. The authors proposed that nigrostriatal dopaminergic input may regulate corticostriatal glutamatergic activity. We have also observed the inhibitory effect of bromocriptine on the sodium-dependent glutamate uptake into synaptosomes; in our experiments, $20 \mu \mathrm{M}$ bromocriptine inhibited about $30 \%$ of the glutamate uptake into synaptosomes in the presence of $50 \mu M$ glutamate. The glutamate reuptake system located on synaptosomal plasma membranes has quite different characteristics from the vesicular glutamate uptake system, particularly with respect to its ability to recognize asparate (Logan and Snyder, 1972; Naito and Ueda, 1985). The inhibitory effects on these two types of glutamate transport systems, one in the synaptic vesicle membrane and the other in the presynaptic plasma membrane, raises the possibility that in vivo short exposure to bromocriptine could prolong or potentiate the glutamate-evoked excitation by inhibiting the reuptake of glutamate from the synaptic cleft. Longer exposures could lead to hypoglutamatergic transmission by depleting vesicular glutamate pools. Because bromocrip- tine is a selective transport inhibitor with reasonable potency, it is also possible that it could serve as a prototype probe in identifying and characterizing the glutamate translocator in a purified synaptic vesicle preparation.

Acknowledgment: This work was supported by grants from the National Science Foundation (BNS 8509679) and the National Institutes of Health (NS 26884).

\section{REFERENCES}

Bradford H. F., Bennett G. W., and Thomas A. J. (1973) Depolarizing stimuli and the release of physiologically active amino acids from suspensions of mammalian synaptosomes. J. Neurochem. 21, 495-505.

Cotman C. W., Foster A. C., and Lanthorn T. H. (1981) An overview of glutamate as a neurotransmitter, in Glutamate as a Neurotransmitter (Di Chiara G. and Gessa G. L., eds), pp. 1-27. Raven Press, New York.

Cotman C. W., Monaghan D. T., Ottersen O. P., and Storm-Mathisen J. (1987) Anatomical organization of excitatory amino acid receptors and their pathways. Trends Neurosci. 10, 273-279.

Fischer-Bovenkerk C., Kish P. E., and Ueda T. (1988) ATP-dependent glutamate uptake into synaptic vesicles from cerebellar mutant mice. J. Neurochem. 51, 1054-1059.

Fonnum F. (1984) Glutamate: a neurotransmitter in mammalian brain. J. Neurochem. 42, 1-11.

Fuxe K., Bredholm B. B., Ogren S.-O., Agnati L. F., Hokfelt T., and Gustafsson J. A. (1978) Ergot drugs and central monoaminergic mechanisms: a histochemical, biochemical, and behavioral analysis. Fed. Proc, 37, 2181-2191.

Fykse E. M. and Fonnum F. (1988) Uptake of $\gamma$-aminobutyric acid by a synaptic vesicle fraction isolated from rat brain. $J$. Neturochem. 50, 1237-1242.

Hell J. W., Maycox P. R., Stadler H., and Jahn R. (1988) Uptake of GABA by rat brain synaptic vesicles isolated by a new procedure. EMBO J. 7, 3023--3029.

Kebabian J. W. and Calne D. B. (1979) Multiple receptors for dopamine. Nature 277, 93-96.

Kish P. E. and Ueda T. (1989) Glutamate accumulation into synaptic vesicles, in Methods in Enzymology, Vol. 174 (Fleischer S. and Fleischer B., eds). Academic Press, New York (in press).

Kish P. E., Fischer-Bovenkerk C., and Ueda T. (1987) Gamma-ami- 
nobutyric acid (GABA) uptake into synaptic vesicles. (Abstr.) J. Neurochem. 48 (Suppl.), S73.

Kish P. E., Fischer-Bovenkerk C., and Ueda T. (1988) Glycine uptake into synaptic vesicles. (Abstract) Trans. Am. Soc. Neurochem. 19, 202.

Kish P. K., Kim S. Y., and Ueda T. (1989a) Ontogeny of glutamate accumulating activity in rat brain synaptic vesicles. Neurosci. Lett. 97, 185-190.

Kish P. E., Fischer-Bovenkerk C., and Ueda T. (1989b) Active transport of GABA and glycine into synaptic vesicles. Proc. Natl. Acad. Sci. USA 86, 3877-3881.

Levi G., Gordon R. D., Gallo V., Wilkin G. P., and Balazs R. (1982) Putative acidic amino acid transmitters in the cerebellum. I. Depolarization-induced release. Brain Res. 239, 425-445.

Logan W. J. and Snyder S. H. (1972) High affinity uptake systems for glycine, glutamic and aspartic acids in synaptosomes of rat central nervous tissues. Brain Res. 42, 413-431.

Lowry O. H., Rosebrough N. J., Farr A. L., and Randall R. J. (1951) Protein measurement with the Folin phenol reagent. J. Biol. Chem. 193, 265-275.

Maycox P. R., Deckwerth T., Hell J. W., and Jahn R. (1988) Glutamate uptake by brain synaptic vesicles. J. Biol. Chem. 263, 15423-15428.

Naito S. and Ueda T. (1983) Adenosine triphosphate-dependent uptake of glutamate into protein I-associated synaptic vesicles. $J$. Biol. Chem. 258, 696-699

Naito S. and Ueda T. (1985) Characterization of glutamate uptake into synaptic vesicles. J. Neurochem. 44, 99-109.

Nicholls D. G. (1989) Release of glutamate, aspartate, and $\gamma$-aminobutyric acid from isolated nerve terminals. J. Neurochem. 52, 331-341.
Nicholls D. G. and Sihra T. S. (1986) Synaptosomes possess an exocytotic pool of glutamate. Nature 321, 772-773.

Nieoullon A., Kerkerian L., and Dusticier N. (1982) Inhibitory effects of dopamine on high affinity glutamate uptake from rat striatum. Life Sci. 30, 1165-1172.

Rall T. W. and Schleifer L. S. (1980) Oxytocin, prostaglandins, ergot alkaloids and other agents, in The Pharmacological Basis of Therapeutics (Gilman A. G., Goodman L. S., and Gilman A., eds), pp. 935-950. Macmillan, New York.

Reubi J. C. and Cuénod M. (1979) Glutamate release from corticostriatal terminals. Brain Res. 176, 185-188.

Russell J. T. (1984) $\Delta \mathrm{pH}, \mathrm{H}^{+}$diffusion potentials, and $\mathrm{Mg}^{2+}$ ATPase in neurosecretory vesicles isolated from bovine neurohypophyses. J. Biol. Chem. 259, 9496-9507.

Shioi J., Naito S., and Ueda T. (1989) Glutamate uptake into synaptic vesicles of bovine cerebral cortex and electrochemical potential difference of proton across the membrane. Biochem. J. 258, 499504.

Storm-Mathisen J., Leknes A. K., Bore A. T., Vaaland J. L., Edminson P., Haug F.-M. S., and Ottersen O. P. (1983) First visualization of glutamate and GABA in neurons by immunocytochemistry. Nature 301, 517-520.

Ueda T. (1986) Glutamate transport in the synaptic vesicle, in $E x$ citatory Amino Acids (Roberts P., Storm-Mathisen J., and Brad. ford H. F., eds), pp. 173-195. Macmillan, London.

Usherwood P. N. R. (1981) Glutamate synapses and receptors on insect muscle, in Glutamate as a Neurotransmitter (Di Chiara G. and Gessa G. L., eds), pp. 183-193. Raven Press, New York.

Watkins J. C. and Evans R. H. (1981) Excitatory amino acid transmitters. Annu. Rev. Pharmacol. Toxicol. 21, 165-204.

Xie X. S., Stone D. K., and Racker E. (1983) Determinants of clathrincoated vesicle acidification. J. Biol. Chem. 258, 14834-14838. 